after some hard searching, but they could usefully have been more obvious while remaining unobtrusive.

A brief guide to the electromagnetic spectrum, and the techniques used to explore phenomena at different wavelengths, rounds off the book. This is not a reference book and not a book

\section{Palaeontological pop}

ThE Christmas dinosaur season is upon us once again. Two major offerings of large format by Richard Moody and Michael Tweedie both have authoritative texts. Moody's Natural History of Dinosaurs (Hamlyn: London; £2.95) has a 29-page introduction that is packed with information, highly condensed and is by no means an easy read. Evolutionary changes are documented but for my money I would have liked to have seen a more extended discussion of the functional aspects, and at least something on the other aspects of the contemporary faunas to give a more rounded picture of the natural history of dinosaurs. There are one or two jarring bits of information. I have never heard of the pelycosaur Dimetrodon having its teeth "differentiated into incisors, canines and cheek teeth" and the occasional purple passage such as certain dinosaurs "grinding mouthfuls of "Mesozoic cud" " have implications with regard to feeding habits that are unfounded. But really I have no quarrel with the author's contribution. It is a worthwhile job well done, given the limited space at his disposal.

The main part of Moody's book is a series of plates with explanatory accompanying texts. The type-face is larger, and the mini-articles are easy to read and surprisingly informative; again the author has done a good job. This book is clearly intended to sell as a picture book, and five different artists have contributed to this. Ann Baum is a most accomplished artist and her illustration of Acanthopholis playing wheelbarrows is far and away my favourite dinosaur illustration. It is a charming picture and leaves one with the impression that the range of dinosaur behaviour was more varied than we had previously imagined. My next favourite is Tony Morris's duckbilled dinosaur Brachylophosaurus shown in a tender embrace of what could only have been the last waltz. A few illustrations are indescribably bad and grossly inaccurate. Finally it is a great shame that there were only two illustrations by Thomas Crosby-Smith. His Mandasuchus feeding on the corpse of a dicynodont in the pouring rain is magnificent. In conclusion, as a picture book, this is very much a curate's egg (good in parts) and I feel that the excellence of the text has not been adequately matched by the artwork. to be read, but it is more than a coffee-table book designed to impress. An intelligent choice of pictures and words makes this a volume that will fascinate and inspire. It is well worth the asking price. Stuart Sharrock

Stuart Sharrock is Physical Sciences Editor of Nature.

The World of Dinosaurs (Weidenfeld and Nicolson: London; Morrow; New York; $£ 4.95 ; \$ 14.95$ ) by Michael Tweedie is clearly the work of an extremely accomplished writer. It is easy to read and gets across a considerable amount of information. Yet, on reading it, one gets a feeling of déjà vu. I suppose Alan Charig and friends should be flattered, but it is clear, at least to my colleagues, that this book is obviously derivative. One should not carp about this too much, for it is done with flair and in itself is an excellent account of dinosaurs. The running text is well illustrated, but interspersed at intervals are large coloured double-page spreads, a few are grossly inaccurate - for example, the ceratopsians the sauropods and the marine shortnecked plesiosaurs. Other illustrations have a familiar ring and I am reminded of Giovanni Caselli proudly claiming that other artists would henceforth use his work as reference material; I am certain he will be suitably gratified to find his prophecy fulfilled.

The last two books are on fossils in general, and in the main are on the kind that anyone can hope to find. Rhona Black's The Observer's Book of Fossils (Frederick Warne: London; $\mathfrak{1 1 . 1 0 )}$ is a neat pocket-sized book of modest price, which, after a concise introduction dealing with many aspects of palacontology, gives a systematic run through of the major groups of fossils with paragraphs on the commoner forms. The line illustrations are perfectly adequate, al-

\section{Megalithic architecture}

The Megalith Builders. By Euan MacKie. Pp. 208. (Phaidon: Oxford, 1977.) Paperback £4.95.

THIS is a popular book, without references in the text either to sources or to the numerous photographic illustrations, which are of varying quality. The colour-plate of Stonehenge (p17) and the aerial photo (p77) and the interior colour view $(\mathrm{p} 88)$ of the West Kennet Long Barrow are laterally reversed. The colour plate on p190 and the cover, ostensibly of Stonehenge near sunset in winter, is a clever photomontage, visually attractive but astronomically impossible, and should have been identified as such. Several of the black-and-white plates are dark, muddy or out of focus. though their positioning at the bottom of each page gives the impression that they were an afterthought popped in just to fill up the page. The complete absence of an index is infuriating and must reduce the utility of this book enormously. The only other criticism I have is in the section on fossil collecting. My own preference is that notebook and pencil and wrapping paper are the prime requirements. So much unnecessary damage is caused at fossil localities by the over-enthusiastic use of hammers and chisels that their use should be positively discouraged; they are hardly ever necessary and do more harm than good. If fossils cannot be collected by hand, they should be left where they are.

With the final book on fossils, we are back to the Christmas market. Richard Moody's The Fossil World (Hamlyn: London; £2.95) is a glossy picture book with attractive colour photographs of fossils. Instead of trundling through one fossil group after another, Moody has dealt with the three major fossiliferous eras: the Palaeozoic (43pp), the Mesozoic (23pp) and the Caenozoic (17pp). The text is of a high standard and reading through it one gains a vivid impression of the changing fortunes of animal life through geological time. Again, I would have preferred rather more on the functioning and behaviour of the organisms he describes. Lots of technical terms suddenly pop up without any explanation and I personally found the sections dealing with bivalves and echinoderms particularly hard going. It was a surprise that the coccoliths as the major component of the Chalk rated not a mention in the Mesozoic section. Basically, I liked this book very much and I hope it does well.

Beverly Halstead

L. B. Halstead is Reader in Geology and Zoology at the University of Reading, UK.

The author's declared aim is to "explain" the megalithic monuments of western Europe in their current chronological contexts. Formerly, it was supposed that megalithic architecture was diffused gradually from the Mediterranean around the western and northern coasts of Europe; but latterly corrected radiocarbon dates (and a series of thermoluminescent dates from Portugal with wide confidence limits, to be used with more caution than the author shows) have tended to imply that the earliest tombs were built on the Atlantic littoral. This is inconsistent with the older model of unidirectional diffusion from Mediterranean or Near Eastern sources of cultural innovation.

The scene is set by eight rather disjointed chapters on regional groups of sites. A surprising inclusion at the beginning is Skara Brae in Orkney, a 